\title{
The perceptions of medical specialists on the influence of Electronic Medical Record use on the quality of hospital care.
}

rube van poelgeest ( $\sim$ rube.van.poelgeest@planet.nl )

Universiteit Utrecht Faculteit Geneeskunde https://orcid.org/0000-0002-5613-242X

\section{Guus Schrijvers}

Universiteit Utrecht Faculteit Geneeskunde

Albert Boonstra

Rijksuniversiteit Groningen

Kit Roes

Radboudumc

Research article

Keywords: Electronic Medical Record (EMR), Hospitals, Quality, Healthcare

Posted Date: March 4th, 2020

DOI: https://doi.org/10.21203/rs.3.rs-16011/v1

License: (c) (i) This work is licensed under a Creative Commons Attribution 4.0 International License.

Read Full License 


\section{Abstract}

Background: Numerous publications show that Electronic Medical Record (EMR) systems may provide an important contribution to increasing the quality and effectiveness of care. There are indications that particularly the medical specialist plays an important role in the implementation of EMR systems in hospitals. Our goal in this study is to answer the question: which positive or negative factors influence, in the perception of medical specialists, the relation between the EMR use and the quality of medical care?

Methods: To answer this question, a qualitative study was conducted in the period August until October 2018. Semi-structured interviews of around 90 minutes were held with twelve medical specialists of twelve different Dutch hospitals. For the analysis of the answers, we used the classification of factors that can influence the implementation of EMR systems based on a previously published taxonomy.

Results: The participating interviewees were experienced medical specialists. Their experience within the hospitals concerned varies between 5 and 27 years. There is a spread across different types of hospitals and specialisms. When the answers received are categorised using a previously published taxonomy, the medical specialist considered technical factors the most significant barriers for EMR use to have a positive effect on quality of care, followed by the suboptimal change processes surrounding implementation. The categories 'social' and 'psychological' and 'time' come in at a shared third place. On the positive side, they also identified potential technical facilitators, particularly in the assured availability of information to all health professionals involved in the care of a patient. They see promise in using EMRs for medical decision support to improve quality of care, but consider these capabilities currently lacking.

Conclusions: In comparison with the paper record, the interviewed medical specialists consider the digitalised record a great leap forward. Every involved health professional can access the patient data if desired at any time they need it. However, in practice, real quality improvement lags behind as long as, for instance, no one uses decision support no one uses decision support, good integrated analytic tools are missing, and the organisation of care is not adapted to these new possibilities.

\section{Background}

In modern-day hospitals, information technology is present in many forms. Among these are information systems, networks, databases and websites. Electronic Medical Record (EMR) systems comprehensively include such technologies to support the medical treatment and care process around patients within the same institution or healthcare system. Various authors agree that these systems can offer an important contribution to increasing the quality and effectiveness of care. (1-3) However, what exactly is the relation between Electronic Medical Record use and the quality of medical care? Previous studies $(2,4,5)$ have attempted to establish links between the extent and the success of implementation of particularly EMR systems and improved quality of medical care. So far, quantitative research has not managed to identify the underlying success or failure factors. There are indications that the role of the medical 
specialist $(6,7)$ is a particularly important factor in the 'adoption and use' (8) of EMR systems in hospitals. Physicians are a main frontline user-group of EMR systems. In addition, whether or not they support and effectively use EMR systems will have a great influence on other user-groups in a medical institution, such as nurses, pharmacists and administrative staff. As a result, physicians have a great impact on the overall adoption level of EMR systems. Hence, it requires physicians to actively support and use EMR systems to benefit optimally from their use. To optimise EMR use, it is essential to understand what physicians perceive to be key factors that either support or hinder the use of EMR systems to positively impact the medical treatment and care that is delivered. Our goal in this study is to answer the question: which positive or negative factors influence, in the perception of medical specialists, the relation between the EMR use and the quality of medical care?

\section{Methods}

To answer the research question, a qualitative research study was performed, essentially spanning 2012 to 2018. A qualitative design was considered appropriate for this question, as the primary objective was to explore more in-depth perceptions on factors and processes that are related to a more complex system including both social and technical components (9)

In the period 2012-2015, the first two authors (RvP and GS) measured the development of EMR use in 73 Dutch hospitals using the so-called EMRAM score (10). This eight-stage (0-7) maturity model measures the adoption and utilization of EMR functions required to achieve a paperless environment that harness technology to support optimised patient care. The hospitals that were measured twice in the research period and received the lowest EMRAM score two at the first measurement in 2012 were asked to participate in the follow-up study in 2018. In December 2017, an additional small local hospital was measured at the highest level (seven). At this level, the hospital is completely paper-free and has advanced functionality implemented like for instance at least three care processes for which the system autonomously initiates actions. (8) This hospital was also measured twice in the period 2012-2015, and was additionally invited to participate, even though it started with EMRAM score 4 in 2012. Due to the availability of two measuring moments for each of the included hospitals, it was possible to assess which changes in EMR use occurred in these hospitals according to the EMRAM model.

Hospitals were approached through the chairs of their medical staff and were asked to each nominate a medical specialist to participate in this study. This specialist had to meet the following criteria: working more than five years in said hospital and support overall a balanced spread across specialisms (surgical, non-surgical, small specialisms).

In the period from August to October 2018, a semi-structured interview of about 90 minutes was held with the relevant medical specialist of the participating hospital. The abovementioned research question was at the heart of this interview. An item list (available from the authors), was used by the interviewer to support the respondents to focus on relevant experiences in case the conversation halted. 
For the analysis of the answers, we used the classification of factors that can influence the implementation of EMR systems based on the taxonomy of Boonstra et al. (11) This systematic literature review was carried out to identify all the barriers that result in physicians showing resistance towards EMR systems. Following this analysis, these barriers are categorised in a taxonomy that has been especially developed for this purpose, in order to gain a wider understanding of them. We used this taxonomy for the same factors in a neutral connotation, as the same taxonomy can be followed categorizing factors as facilitators. Three of the four authors (RvP, GS and KR) have participated in the allocation of a certain aspect to a factor of the described taxonomy, with assessment spilt in initial allocation by the first author and validation by the second and third. The results were recorded in an Excel-file that is available on request from the first author. Based on this classification and the primary interview recordings, the authors (RvP, GS and KR) reached consensus on eight pre-concepts about the best way to allocate quotes to the categories of the taxonomy. All authors agreed with the final allocation of quotes.

\section{Results}

Prior to the interviews the extent of EMR use of all selected hospitals was recalibrated. This shows that some hospitals remained at EMRAM score 2 since 2014, particularly because they do not use a digital nursing record. Others rose to higher levels. Some hospitals merged, resulting in fifteen hospitals meeting the selection criteria for the present study, additionally including the hospital that reached EMRAM level 7, while starting at level 4 in 2012. Twelve hospitals (Table 1) subsequently agreed to participate in this qualitative study. Three hospitals (one regional and two teaching hospitals) were not willing or not able to participate.

Each participating hospital nominated one medical specialist to be interviewed, representing 10 different medical areas and between 5 to 27 years of experience in their current hospital (Table 2). In total, respondents mentioned 160 factors that influence the relation between the extent of EMR use and the quality of care. 122 factors were characterised as 'barrier' and 38 as 'facilitator' (Table 3).

\section{The technical factors}

The 'technical factors' are mentioned most often ( 96 times), of which 65 times as 'barrier' and 31 times as 'facilitator'. Table 4 therefore shows a subdivision of the technical factors (11), followed by exemplary quotes from respondents to provide more insight in the underlying insights.

\section{Customisability}

Within the category 'technical', 'customisability' is mentioned most often (55 times), more often as 'facilitator' than as 'barrier'. A medical specialist of a local hospital (respondent 7) observes: "Back in the day, the paper records often got lost. Lab results are available more quickly now and the medical specialist can quickly see the daily reports of the nurses (facilitator)". And another says "innumerable positive points; accessible everywhere, even at home. No more illegible notes (facilitator)" (respondent 
10). And because no paper file anymore but "It is digital, but that about says it all. Leaves much to be desired, though (barrier)" (respondent 9). And a medical specialist of a University Medical Centre adds (respondent 2) "Not intuitive. Terrible user interface. Unpleasant system, it clearly hasn't been primarily designed for doctors and paramedics. An originally administrative system that has been reshaped into a medical system (barrier)". "We can see the added value, but these systems are shoddy. Not intuitive (barrier)" (respondent 8). And respondent 2 "Negative: preoperative polio. Supplementary lab research takes 1-2 days. If you want to change policy based on the results, the EMR system shows that this is impossible because the patient has not been hospitalised but is not present at the outpatient clinic either (barrier)".

\section{Interconnectivity/standardisation'}

The 'interconnectivity/standardisation' of the system is also an important topic. It is mentioned 15 times, of which 13 times as 'barrier'.

A gynaecologist from a local hospital (respondent 9) states: "Gynaecologists work with 4 systems (safety risk), because systems are not interlinked (barrier)". And respondent 11 states: "Using many separate systems poses a great risk because they are not linked to our EMR system regarding the transfer of records (barrier)". But also, "Positive: back in the day, there was no background information available if the GP's notification read 'diarrhoea', now there is (facilitator)" (respondent 5).

\section{Limitation of the system}

The 'limitation of the system' is mentioned 15 times of which 14 times as a 'barrier'. According to the respondents, these systems promise a great deal but offer little more than the old situation. Respondents particularly point to the promised additional intelligence, the help the system could offer so-called 'evidence-based' material based on the individual and combined patient data available in the system (12). About this, respondent 4 states: "Intelligence systems fall short. Before the transformation, paper records would have a yellow post-it: pay attention! Responsibilities in the system are becoming increasingly regulated. Overabundance of authorisations is necessary because system demands this (e.g. medication). System should be able to make its own decisions (compare yellow post-it). Medical specialist becomes overworked, because support has disappeared due to EMR use (barrier)". An internist from a teaching hospital (respondent 5) is more positive: "There is a little bit of decision support for medication (prescriptions) (facilitator)". But respondent 10 states: "Frustration: patient comes to me with additional info (e.g. Fitbit). Cannot enter data into system (barrier)". An oft-heard theme is the lack of analytic tools to analyse the entered data (analytics). A surgeon (respondent 8 ) from a local hospital, who also operates on patients referred by him to a University Medical Centre and who performed his own analyses on the countrywide available data by 'hand', states about the potential of good analytic tools: "Quality potentially improves through registration, but it is not used yet. Take, for example, cancer registrations: gastrointestinal surgery was compared with other hospitals; too many complications; painkillers scrapped; this provides lower mortality, now we are best of class (barrier)". And respondent 9 , who addressed the same issue of the unavailability of good analytic tools by end users adds: "Executing 
the analysis was very time consuming. Analytics have to be carried out by an IT-specialist. This makes it a hopeless affair. These tools should be included in the EMR (barrier)".

\section{The 'change process'}

The 'change process' is mentioned 30 times of which two times as 'facilitator'. The role of the IT specialists and the software providers is mentioned frequently. "......... (EMR supplier mentioned) does not listen to the customer (barrier)" (respondent 4). And with regards to the role of the medical specialists themselves: "Before, medical specialists were individual, had their own working methods. By now, a technological revolution has taken place (paper records are now electronic records). But people do not want to change (95\%). They have to get out of their comfort zone. You have to invest in that. Now: medical specialists' approach EMR as if it were paper (barrier)" (respondent 10). A central theme for almost all interviewed medical specialists is the coded or non-coded recording of obtained information. A number of hospitals have initially started out with the recording of this information by medical specialists, but have later abolished this system because the medical specialist want to keep their options open as trained, "80-90\% was filled out in the check box 'other' (plain text)", "in other words, doctors should not be the one to fill out these structured questionnaires, this should be left to the nursing specialist, or an outpatient clinic assistant together with a patient, since they know exactly what to ask" "Conclusion: recording by medical specialist is undesirable, but it is necessary to enable systems to 'offer help' on a more advanced level. This process should be structured differently by giving supporting staff a role in it (barrier)" (respondent 8).

\section{The factor 'psychological'}

The factor 'psychological' is mentioned 11 times. One of the respondents states that "Doctors are stubborn and have seldom put their needs down on paper (barrier)" (respondent 2). A paediatric neurologist also sees a distinction between old and young medical specialists, whereby he states, "there is a contrast between old and young specialists: I think the older ones accept a system more easily, their demands are less high (barrier)" (respondent 7). Some things are perceived as positive, though: "enforces a certain treatment and that is positive (facilitator)" (respondent 10). Apparently, this treatment has been agreed within the professional group of the medical specialists concerned.

\section{The factor 'time'}

The factor 'time' is mentioned 11 times, of which twice as 'facilitator'. Key focus lies on a remark from a University Medical Centre (respondent 2): "....it costs five extra hours of work a week (barrier)".

Nevertheless, the factor 'time' is also experienced in a positive sense. A paediatric neurologist (respondent 7) states "Productivity increases (facilitator)" and a pharmacist (respondent 11) says "Fewer staff, saves us 2 minutes per patient (facilitator)".

\section{The factor 'social'}


Medical specialists perceive the factor 'social' mainly as a barrier (eight times) and twice as facilitator. A paediatric neurologist of a local hospital states that he has to see the patient intensively: "Anamnesis is very important for a neurologist; head-turning-syndrome, for instance, can only be recognised through observation of the patient (barrier)" (respondent 7). A side effect is articulated by a radiologist of a teaching hospital "Back in the day, photos sometimes disappeared (dangerous), but medical specialists came to radiology because there was only one photo, this meant people knew each other, radiology was the centre, people walked in, it used to run more smoothly, now there is multidisciplinary consultation, but people don't know each other anymore (barrier)" (respondent 4).

The focus lies on the relationship with the patient, which a cardiologist (respondent 10) expresses as follows "Negative influence on doctor-patient relationship through administrative burden (barrier)". Politics also play a role, says respondent 2 of an academic hospital: "I am unhappy about the bad influence of politics/the government (barrier)". And the same respondent also states about the role of management: "Hospital boards have insufficient insight into the needs of physicians and paramedics (barrier)".

\section{The factor 'financial'}

The factor 'financial' is mentioned twice. Two respondents of small hospitals note: "...... (EMR supplier mentioned) is 'sexy' but expensive (barrier)" (respondent 12) and "we have not looked at (EMR supplier mentioned), it is too expensive (barrier)" (respondent 9).

\section{Limitations Of The Study}

Our study has several limitations. The main disadvantage of qualitative analyses is that their findings cannot be easily extended to wider populations with the same degree of certainty as quantitative analyses. The main objective of this study was to detect factors. Assessing their overall impact more generally requires quantitative confirmation.

Only hospitals have been interviewed in which an EMRAM score 2 was measured in 2012. These hospitals found themselves in the lowest stage of EMR use according to the EMRAM model, but also with large potential to improve effectively and in a position to have learned from other hospitals before the interviews. However, this qualitative study might still have been too early in the hospital's implementation of EMR to identify factors that are relevant for mature use of EMRs.

The age of the interviewed medical specialists varies between 42 and 62 years. These are medical specialists with a great deal of experience in the field. A question is whether the perception of younger medical specialists corresponds with the perception of their older colleagues. Follow-up research might answer this question.

\section{Discussion}


The overall picture of the relation between the extent of EMR use and the quality of medical care in the perception of the medical specialist shows that respondents prefer digital over the old paper records. However, at the same time, respondents consider the technical systems old-fashioned compared to the systems they can access at home to book a trip or buy a book. The inability of all those involved (professional groups, boards, suppliers, politicians) to improve this situation is described openly by some participants. By and large, respondents do see the potential, but a way to record coded information still needs to be found. The lack of interconnection of systems is also seen as an important limitation. Eventually, these systems should be able to offer support in diagnostics and treatment. And that is not as easy as it may sound. This is not a remarkable result and tallies with the results of other studies. $(13,14)$.

Noteworthy is that financial aspects are not mentioned often (two times). This contrasts with other studies, in which 'technical issues' and 'financial issues' are mentioned in equal measure. (12) The obvious question is then whether "money does not play a role" in the perception of the medical specialist. Follow-up research might answer this and other questions.

\section{Conclusions}

In comparison with the paper record, the interviewed medical specialists consider the digitalised record a great leap forward. Every involved health professional can access the patient data if desired at any time they need it. However, in practice, real quality improvement lags behind as long as, for instance, no one uses decision support, good integrated analytic tools are missing, and the organisation of care is not adapted to these new possibilities.

\section{Declarations}

\section{Availability of data and materials}

The datasets generated and/or analysed during the current study are available, after anonymisation, from the corresponding author on reasonable request.

\section{Ethics approval and consent to participate}

As this study did not involve research on patients or human subjects, no Medical Ethical Committee approval was required under Dutch law. Neither the Dutch Medical Research Involving human subjects Act (WMO), Wet Medisch-Wetenschappelijk onderzoek met mensen, nor the University required ethics approval for the type of work conducted in this research. All interviewees orally and voluntarily agreed to participate in this study. They allowed us and to use the data they provided, including the use of quotes, under the condition of confidentiality.

\section{Consent for publication}

All interviewees participated on a voluntary basis and were granted confidentiality. All respondents have agreed with the final report of their interviews. As participating hospitals, medical specialists and used 
quotes in the manuscript were anonymized

no written permission was needed in this case.

\section{Competing interests}

The authors declare that they have no competing interests.

\section{Funding}

No funding was acquired. All authors declare no conflict of interest.

\section{Authors' contributions}

RvP planned and conceptualised the study, developed the interview guide, acquired data, analysed and interpreted data, and drafted the manuscript. GS assisted in developing the interview guide and was involved in the interpretation of data and in preparing an early version of the manuscript and revised the manuscript. AB assessed the adapted use of the taxonomy as published in (11). KR supervised the study. All authors read and approved the final manuscript.

\section{Acknowledgements}

The authors wish to thank Leonard Witkamp, professor of telemedicine at the UMC Amsterdam for his valuable early review of the article.

\section{Abbreviations}

EMR use: EMR use generally alludes to the transition of information to a digital form, that is, in a form that can be used by electronic devices such as computers. In this article the term can concern the data itself, or the accompanying procedures, or a fundamental change of method (so-called digital transformation)

\section{References}

1. Lin YK, Lin M, Chen H. Do electronic health records affect quality of care? Evidence from the $\mathrm{HITECH}$ act. Inf Syst Res. 2019;

2. van Poelgeest, Rube, Daniels, John, de Leeuw, Rob J., Schrijvers G. Profile of the digitization of patient medical records in Dutch hospitals. J Healthc Inf Manag [Internet]. 2015 [cited 2019 Jan 19]; (Fall 2015):38-9. Available from: http://www.jhimdigital.org/jhim/fall_2015?pg=38\#pg38

3. Wani D, Malhotra M. Does the meaningful use of electronic health records improve patient outcomes? J Oper Manag. 2018;

4. van Poelgeest R, van Groningen JT, Daniels JH, Roes KC, Wiggers T, Wouters MW, et al. Level of Digitization in Dutch Hospitals and the Lengths of Stay of Patients with Colorectal Cancer. J Med 
Syst. 2017;41(5).

5. Poelgeest R Van, Heida J, Pettit L, Leeuw RJ De. The Association between eHealth Capabilities and the Quality and Safety of Health Care in The Netherlands: Comparison of HIMSS Analytics EMRAM data with Elsevier 's ' The Best Hospitals ' data . :1-9.

6. Lakbala P, Dindarloo K. Physicians' perception and attitude toward electronic medical record. Springerplus [Internet]. 2014;3(1):63. Available from: http://www.pubmedcentral.nih.gov/articlerender.fcgi? artid $=3918096 \&$ tool $=$ pmcentrez\&rendertype $=$ abstract

7. Ankem K, Turpin J, Uppala V. Physician adoption of electronic health records: A visualisation of the role of provider and state characteristics in incentive programme participation. Inf Res. 2016;

8. Electronic Medical Record Adoption Model (EMRAM) [Internet]. Healthcare Information and Management Systems Society (HIMSS), Chicago. [cited 2015 Jan 15]. Available from: www.himssanalytics.org/emram/emram.aspx (2014)

9. Yin RK. Qualitative research from Start to Finish. THE GUILFORD PRESS New York London. 2011.

10. Pettit L. Understanding EMRAM and how it can be used by policy-makers, hospital CIOs and their IT teams. ... Off J Int Hosp Fed [Internet]. 2012 [cited 2015 Jun 1]; Available from: http://europepmc.org/abstract/med/24377140

11. Boonstra A, Broekhuis M. Barriers to the acceptance of electronic medical records by physicians from systematic review to taxonomy and interventions. BMC Health Serv Res [Internet]. 2010 Dec 6 [cited 2019 Feb 14];10(1):231. Available from: http://www.ncbi.nlm.nih.gov/pubmed/20691097

12. Frankovich J, Longhurst CA, Sutherland SM. Evidence-based medicine in the EMR era. New England Journal of Medicine. 2011.

13. Boonstra A, Versluis A, Vos JFJ. Implementing electronic health records in hospitals: A systematic literature review. BMC Health Serv Res [Internet]. 2014;14(1):370. Available from: http://www.biomedcentral.com/1472-6963/14/370

14. Kruse CS, Kristof C, Jones B, Mitchell E, Martinez A. Barriers to Electronic Health Record Adoption: a Systematic Literature Review. J Med Syst. 2016;

\section{Tables}

\section{Table 1 - Summary of participating hospitals based on EMRAM-score}




\begin{tabular}{|c|c|c|c|c|}
\hline $\begin{array}{c}\text { Respondent } \\
\text { number }\end{array}$ & Name & $\begin{array}{c}\text { EMRAM1 } \\
(2012)\end{array}$ & $\begin{array}{c}\text { EMRAM2 } \\
(2014)\end{array}$ & $\begin{array}{c}\text { EMRAM3 } \\
(2018)\end{array}$ \\
\hline 1 & UMC & 2 & 2 & 2 \\
\hline 2 & UMC & 2 & 6 & 7 \\
\hline 3 & $\begin{array}{l}\text { teaching } \\
\text { hospital }\end{array}$ & 2 & 2 & 2 \\
\hline 4 & $\begin{array}{l}\text { teaching } \\
\text { hospital }\end{array}$ & 2 & 5 & 5 \\
\hline 5 & $\begin{array}{l}\text { teaching } \\
\text { hospital }\end{array}$ & 2 & 2 & Not available \\
\hline 6 & $\begin{array}{l}\text { teaching } \\
\text { hospital }\end{array}$ & 2 & 5 & 5 \\
\hline 7 & local hospital & 2 & 5 & 1 of 2 \\
\hline 8 & local hospital & 2 & 2 & 5 \\
\hline 9 & local hospital & 2 & 2 & 5 \\
\hline 10 & local hospital & 2 & 2 & 3 \\
\hline 11 & local hospital & 2 & 6 & 6 \\
\hline 12 & local hospital & 4 & 4 & 7 \\
\hline \multicolumn{5}{|c|}{$\begin{array}{l}\text { UMC = University Medical Centre: includes teaching hospital with Faculty of Medicine and research centres. There are } 7 \text { UMCs in The Netherlands. } \\
\text { teaching hospitals are important training centres for physicians that also provide complex care, in addition to basic care. These hospitals are specialised in } \\
\text { one or several healthcare areas. These larger hospitals receive patients from a larger geographical area than the smaller, general hospitals. There are } 26 \\
\text { teaching hospitals in The Netherlands. } \\
\text { local hospitals provide basic care. There are } 45 \text { local hospitals in The Netherlands. }\end{array}$} \\
\hline
\end{tabular}

Table 2 - Summary participating respondents 


\begin{tabular}{|c|c|c|c|c|c|c|}
\hline $\begin{array}{c}\text { Type } \\
\text { hospital }\end{array}$ & Number & $\begin{array}{l}\text { Number of } \\
\text { specialists }\end{array}$ & $\begin{array}{c}\text { Respondents (nr) } \\
6 \text { of which (former) chair of } \\
\text { medical staff }\end{array}$ & Age & Gender & $\begin{array}{c}\text { Number of years of } \\
\text { experience in hospital }\end{array}$ \\
\hline UMC & 2 & $732-1050$ & $\begin{array}{l}\text { internist (1) } \\
\text { anaesthetist (2) }\end{array}$ & $\begin{array}{l}43 \\
-57\end{array}$ & $\begin{array}{l}1 \\
\text { female } \\
1 \text { male }\end{array}$ & $10-13$ \\
\hline $\begin{array}{l}\text { Teaching } \\
\text { hospital }\end{array}$ & 4 & $240-377$ & $\begin{array}{l}\text { surgeon (6) } \\
\text { radiologist (4) } \\
\text { internist (5) } \\
\text { rheumatologist (3) }\end{array}$ & $\begin{array}{l}49- \\
62\end{array}$ & $\begin{array}{l}2 \text { males } \\
2 \\
\text { females }\end{array}$ & $11-23$ \\
\hline $\begin{array}{l}\text { local } \\
\text { hospital }\end{array}$ & 6 & $70-187$ & $\begin{array}{l}\text { vascular surgeon (8) } \\
\text { paediatric neurologist (7) } \\
\text { gynaecologist (9) } \\
\text { anaesthetist (12) } \\
\text { pharmacist (11) } \\
\text { cardiologist (10) }\end{array}$ & $\begin{array}{l}42- \\
59\end{array}$ & 6 males & $5-27$ \\
\hline
\end{tabular}

Table 3 - Summary of categories mentioned by participating respondents 


\begin{tabular}{|c|c|c|c|c|}
\hline $\begin{array}{c}\text { Quote } \\
\text { category }\end{array}$ & description & $\begin{array}{c}\text { total } \\
\text { number }\end{array}$ & $\begin{array}{c}\text { of } \\
\text { which } \\
\text { barrier }\end{array}$ & $\begin{array}{c}\text { of which } \\
\text { facilitator }\end{array}$ \\
\hline 'technical' & $\begin{array}{c}\text { the technical aspects of the systems, the } \\
\text { technical capabilities of the physicians and } \\
\text { the suppliers }\end{array}$ & 96 & 65 & 31 \\
\hline $\begin{array}{c}\text { 'change } \\
\text { process' }\end{array}$ & $\begin{array}{c}\text { The influence of the organisational culture, } \\
\text { incentives, community level participation } \\
\text { and leadership }\end{array}$ & 29 & 27 & 2 \\
\hline 'psychological' & $\begin{array}{c}\text { personal issues, knowledge, and } \\
\text { perceptions }\end{array}$ & 11 & 10 & 1 \\
\hline 'social' & $\begin{array}{c}\text { The relation with the patient and fellow } \\
\text { care providers, but also with suppliers, } \\
\text { insurers and politicians. }\end{array}$ & 11 & 9 & 2 \\
\hline 'time' & $\begin{array}{c}\text { time required to select, implement and } \\
\text { learn how to use EMR systems, and then to } \\
\text { enter data into the system }\end{array}$ & 11 & 9 & 2 \\
\hline 'financial' & $\begin{array}{c}\text { financial issues including those related to } \\
\text { the monetary issues involved in } \\
\text { implementing EMR systems }\end{array}$ & 2 & 2 & 0 \\
\hline Total number \\
of quotes
\end{tabular}$\quad$\begin{tabular}{c}
160 \\
\hline
\end{tabular}

Table 4 - Subdivision category 'technical' 


\begin{tabular}{|c|c|c|}
\hline Subcategory technical & description & 96 \\
\hline customisability & $\begin{array}{l}\text { refers to the ability of the technology system } \\
\text { to adapt to specific needs of the user }\end{array}$ & 55 \\
\hline barrier & & 29 \\
\hline facilitator & & 26 \\
\hline interconnectivity/standardisation & $\begin{array}{l}\text { EMR hardware and software cannot be used } \\
\text { straight "out of the box", it has to } \\
\text { interconnect with other devices that } \\
\text { "complement" the EMR system }\end{array}$ & 15 \\
\hline barrier & & 13 \\
\hline facilitator & & 2 \\
\hline limitation of the system & $\begin{array}{l}\text { the systems can reach their limitations, } \\
\text { become obsolete and will no longer be useful }\end{array}$ & 15 \\
\hline barrier & & 14 \\
\hline facilitator & & 1 \\
\hline complexity & $\begin{array}{l}\text { EMR systems result in physicians having to } \\
\text { allocate time and effort if they are to master } \\
\text { complexity }\end{array}$ & 1 \\
\hline barrier & & 1 \\
\hline $\begin{array}{l}\text { computer skills of the physician and/or } \\
\text { staff }\end{array}$ & $\begin{array}{c}\text { technical knowledge and skills to deal with } \\
\text { EMR systems }\end{array}$ & 2 \\
\hline barrier & & 2 \\
\hline reliability & the dependability of the technology systems & 2 \\
\hline barrier & & 1 \\
\hline facilitator & & 1 \\
\hline training and support & $\begin{array}{l}\text { training and support associated with the EMR } \\
\text { systems }\end{array}$ & 6 \\
\hline barrier & & 5 \\
\hline facilitator & & 1 \\
\hline
\end{tabular}

\section{Supplementary Files}

This is a list of supplementary files associated with this preprint. Click to download.

- COREQchecklistversion2.pdf

- Surveyprotocol.pdf 